\title{
Assessment of Innovative Strategies on Service Delivery at the National Hospital Insurance Fund Nakuru, Kenya
}

\author{
Earnest Seme Nyaberi ${ }^{1}$, Dr. Josphat Kwasira ${ }^{2}$ \\ ${ }^{1,2}$ Department of business School of Human Resource Development, Jomo Kenyatta University of Agriculture and Technology, Juja, Kenya
}

\begin{abstract}
Globally the business environment is rapidly changing due to current trends of technological upheavals, economic fluctuations and shifts in labour movement all with public demands for better services. All this has necessitated organizations to embrace various innovation strategies with the aim of constantly improving service delivery to customers. This justifies the present study that assessed the influence of innovative strategies on service delivery at the National Hospital Insurance fund, Nakuru. In particular, study sought to assess various innovative strategies adopted by the organization's 2014/2017 strategic plan to improve servic e delivery in terms of benefits, accessibility and growth in membership. The study was guided by stakeholder theory, technology acceptance theory and Institutional theory. In addition, the study adopted a descriptive research design. Census sampling technique was employed in the study to gather information from the 60 employees of NHIF, Nakuru branch. Structured questionnaires pilot-tested and further administered. Data collected was analyzed using descriptive and inferential statistics with the aid of the Statistical Package for Social Sciences version 20. A Pearson correlation analysis and a linear regression analysis were done. The correlation analysis done indicated positive correlations between all the independent variables (Biometric registration techniques, central connectivity, electronic funds transfer payments and open office layout adoption) and the dependent variable (Service delivery). Based on the results of the regression analysis, the first null hypothesis was rejected since the Biometric registration techniques were found to be having significant positive influence on service delivery at NHIF Nakuru branch. The fourth null hypothesis was also rejected since the study found out that the Open office layout had significant positive effect on service delivery at National Hospital Insurance fund, Nakuru. However, in tandem with the second and the third null hypotheses, central connectivity and electronic funds transfer payments respectively did not show significant effect on service delivery at NHIF. It was recommended that the organization should enhance its central connectivity systems and leverage its use of electronic funds transfer payments to improve the quality of service delivery. The study finding will be used by NHIF and other similar organization in enhancement of service delivery.
\end{abstract}

Keywords: Innovative strategies, Biometric techniques, Central connectivity, Electronic Money Transfers, Open Office layout and service delivery.

\section{Introduction}

\subsection{Background of the Study}

National Hospital Insurance Fund (NHIF) is a state corporation that is authorised to receive contributions from self-employed and salaried employees who subsequently get entitled to health insurance benefits in the event of being hospitalized. NHIF has strived to extend its social health insurance cover to as many Kenyans as possible and has opened 66 branches across the country. Just like other corporate bodies operating in the free market, NHIF has not been immune from competition. There has been intense competition from the private insurance companies that offer health insurance products. In fact, quite a majority of the members of NHIF come from the formal sector while only a small percentage is from the non-formal sector.

A report issued by World Bank Group Investment Climate (2014) indicates that by the year 2008, NHIF had 2,175,255 members where only 253, 267 members (11.6\%) were from the non-formal sector while the other 1,921,985 members (88.4\%) were from the formal sector (WBGIC, 2014). As at 2015 the membership had risen to 6, 325,060 as reflected in the strategic plan 2014/2017.Private insurance firms share increased in number and thus stiffened competition driven by innovative and the ever changing market conditions. Banks have also come up with various innovative bancassurance products eyeing the same market that NHIF seeks to serve.

This statistics indicates that apparently the private insurance organizations control a larger market share and present better returns to the customers served. On the contrary, the NHIF benefits are limited and thus many customers prefer subscribing to the private insurers. As a result this justifies the low membership growth at NHIF and therefore necessitates the introduction of innovative strategies to improve service delivery and customer satisfaction rates.

This study seeks to uncover the influence of innovative strategies geared towards enhancing service delivery.The contemporary dynamic business environment characterized by economic restructuring, advancement in technology and dwindling market demands forces organizations to rethink the business strategies and innovate to gain sustainable competitive advantage.

The National Hospital Insurance Fund of Kenya (NHIF) is not left behind in this course. The organization has gone through several transformations aimed at ensuring timely service delivery (WBGIC, 2014). The recent transformation comes from the innovative strategies contained in the 2014/2017 strategic plan which also outlines various service innovations the organization makes in order to serve the customers better. In fact, the contemporary dynamic business environment necessitates strategic innovation of products, 


\section{International Journal of Science and Research (IJSR) \\ ISSN (Online): 2319-7064}

Index Copernicus Value (2013): 6.14 | Impact Factor (2015): 6.391

services and processes with a focus on customers, the organization's competitive capabilities for purposes of gaining competitive advantage in the market.

Before delving into NHIF's innovative strategies, it is important to understand the concept strategy, innovation and further outline various innovative strategies used both in the public and private sectors. According to Pisano (2015) a strategy is nothing more than a commitment to a set of coherent, mutually reinforcing policies or behaviors aimed at achieving a specific competitive goal. Strategy is the direction and scope of an organization over the long-term (Maharshi Dayanand University, Rohtak, 2004). Good innovative strategies promote alignment among diverse groups within an organization; clarify objectives and priorities, and help focus efforts around them. Organizations regularly define their overall business strategy (their scope and positioning) and specify how various functions - such as marketing, operations, finance, and R\&D-will support it. However, some firms rarely articulate strategies to align their innovative efforts with their business strategies (Pisano, 2015: Bhargava \& Welford, 2009). In general, strategy seeks to achieve advantage for the organization through its configuration of resources within challenging environment to meet the needs of markets and to fulfill stakeholders' expectations (Bhargava, \& Welford, 2009). In other words, strategy is about direction, scope, advantage, resources, environment and stakeholders.

\subsection{Statement of the Problem}

Of late insurance and health care sectors in Kenya have been working hand in hand to offer exceptional services and improve the livelihoods of the citizens. Technological advancements across different sectors of the economy have necessitated vast competition and only organizations that are capable of leveraging on technology using appropriate innovative strategies survive and perform well. The adoption of innovative strategies presents vast advantages to organizations including improved profitability, competitive advantage, and market share growth among others. Organizations that do not adopt appropriate innovative strategies record poor performance and sometimes close down due to failure to adapt to the dynamic market conditions. National Hospital Insurance Fund (NHIF) being a service organization has undergone several transformations aimed at real time service delivery. However, there is slow response to the various innovative strategies launched in a bid to attract more members and improve service delivery. Only few members have enrolled despite the Kenya's population of over 40 million people. Statistics indicate that as at the year 2008 NHIF had only registered of 2,175,255 members against the estimated 8.7 million people that were capable of raising the required premiums. During that year, NHIF had a total membership of 2,175,255 where only 253, 267 members (11.6\%) were from the non-formal sector. The remaining 1,921,985 members (88.4\%) were from the formal sector. As at 2015 the membership had risen to 6, 325,060 as reflected in the strategic plan 2014/2017 contrary to the estimated possible 18 million members. This scenario is a manifestation of a big strategic gap that calls for an urgent redress if real time service delivery at the Fund is to be realized. The organization has since come up with a myriad of innovative strategies to help boost its active membership and hence further the need to increase competitiveness and performance in the dynamic environment. Some of the innovative strategies used include the adoption of biometric registration techniques, central connectivity, the use of electronic fund transfer and adoption of an open office layout to enhance service delivery. Therefore, it is of utmost importance that studies on innovative strategies and their influence on service delivery be conducted. These strategies offer numerous benefits to the organization in terms of increased business, higher revenue collection, enhanced customer satisfaction, increased membership, and market share growth among others. However, it is argued that there exist a dismal number of empirical studies on the influence of innovative strategies on service delivery by NHIF. This study thus sought to assess the influence of various innovative strategies on service delivery at the NHIF, Kenya

\subsection{Objectives of the Study}

1)To determine the influence of biometric registration technique on service delivery at NHIF Nakuru branch.

2)To evaluate the influence of central connectivity on service delivery at NHIF Nakuru branch.

3)To establish the influence of Electronic Fund Transfer on service delivery at NHIF Nakuru branch

4)To analyze the influence of open office layout on service delivery at NHIF Nakuru branch.

\subsection{Research Hypotheses}

Ho1: Biometric technique does not have significant influence on service delivery at NHIF Nakuru branch.

Ho2: Central Connectivity does not have significant effect on service delivery at NHIF Nakuru branch.

Ho3: Electronic Funds Transfer does not have effect on service delivery at NHIF Nakuru branch.

Ho4: Open office layout does not have significant effect on service delivery at NHIF Nakuru branch,

\section{Literature Review}

\subsection{Theoretical Review}

The sub section expounds on the major theories underpinning the study. The theories offer a base for the conceptualization of the variables under study. The study was guided by stakeholder theory, technology acceptance theory and Institutional theory. On the basis of their applicability to this study, these theories seek to enhance a thorough understanding of how NHIF's innovative strategies influence service delivery.

\subsubsection{Stakeholder Theory of Management}

The stakeholder theory was first developed by Freeman in 1980. The theory explains a stakeholder as a group of people or an individual with interest in an organization. In this regard, the stakeholder can directly or indirectly be affected by the actions, objectives, policies and strategies of the organization and vice versa. A stakeholder can be an 


\section{International Journal of Science and Research (IJSR) \\ ISSN (Online): 2319-7064}

Index Copernicus Value (2013): 6.14 | Impact Factor (2015): 6.391

employee, supplier, shareholders, customer or a member of the board of directors. The stakeholder theory states that a business should attach great value to the stakeholder (who, in this case include the customer, employees and the entire organization offering the services), because without this stakeholder's support the organization would collapse or cease to be sustainable (Donaldson \& Preston, 1995). This is partly because the NHIF's customers are the reason the organization exists since it is for them that the services are designed, created and delivered. In delivering its services, the organization relies on its employees and strategic partners who offer the services to the customers. It is, therefore, important for the executives of the organization to keep the interest of all stakeholders aligned and gear them in the same direction. The theory has three aspects that mutually support each other i.e. the instrumental approach, normative approach and the descriptive approach. The instrumental approach is for identifying the connection between achievement of corporate goals and the group of stakeholder management using empirical data.

The normative approach is considered to be the most important aspect because it identifies the moral and physiological guidelines for strategy, operations and management of an organization. In the descriptive approach, it explains the characteristics of firms and also the inherent behaviors' (Donaldson \& Preston, 1995). The theory's core function is to establish the balance of the interests for the different stakeholders and so for this to be accomplished the stakeholders must be identified. This theory applies to this study as it enhances the consideration of the interests and capabilities of the customer, employees and NHIF as the key stakeholders for whom the efficient and effective service delivery is meant.

\subsubsection{Technology Acceptance Model}

Davis (1985) adapted the Theory of Reasoned Action (TRA) model to the context of user acceptance of the information system in order to develop the Technology Acceptance Model (TAM). In his work, he talks about two distinct beliefs, perceived usefulness and perceived ease of use, which, had been identified as being sufficiently enough to predict the attitude of a user toward use of a system (Chuttur, 2009). Davis (1989) model suggested that when "a user is presented with a new technology, a number of factors influence their decision regarding how and when they will use it" (Manueli et al., 2007). With regards to NHIF innovative strategies, the innovative characteristics, notably perceived usefulness and perceived ease of use as defined by Davis, (1985), perceived usefulness is the degree to which an NHIF employee believes using a particular innovation would enhance his or her job performance. On the other hand, perceived ease of use is "the degree to which when an NHIF employee believes that using a particular innovation would be free of physical and mental effort." This is the theory which explains how an employee works to ensure the success of innovative strategies of the organisation.

\subsubsection{Institutional Theory}

Institutional theory was developed from the works of Meyer and Rowan (1977) and DiMaggio and Powell (1983). The Institutional theorists postulate that organizations' members are obliged to conform to the institutions' environment within which they operate and that the institutional environment can influence the development of formal structures in an organization more profoundly than market pressures. In this case, the institutional environment comprises the factors that drive change in the organization. Innovative structures that improve technical efficiency of organizations are legitimized in the environment and in the long run, the new and existing organizations adopt the structural form even if the form doesn't improve efficiency. The institution stands guided by a set or of rules, regulations and procedures that function as rationalized "institutional myths" in order to bring sanity, order and stability. A study conducted by Sossion (2015) reveals that often these "institutional myths" are merely accepted in order for the organization to gain or maintain legitimacy in the operational environment. In the context of NHIF, this theory applies as it depicts a set of rules, regulations, standards and procedures that are binding to all stakeholders in line with delivering on institutional mandate. The sanctity of such procedures, standards and mandatory requirements confers more legitimacy to the institution and enhances stability even during challenging situations.

In addition, Organizations adopt structural changes in their environment in form of specific job titles, procedures, and organizational roles. In fact, the adoption and prominent display of these institutionally-acceptable "trappings of legitimacy" help preserve an aura of organizational action based on "good faith" to ensure continued improvements in service delivery and sustainable organizational survival. However, these formal structures of legitimacy are subject to political manipulation and other factors that can reduce efficiency hence inhibiting the quality of customer service. This theory applies to the use of innovative strategies in enhancing service delivery at NHIF, Nakuru.

\subsection{Empirical Review}

The independent and dependent variable were broken down into indicators. The indicators on innovative strategies and service delivery are discussed in this subsection.

\subsubsection{Biometric techniques}

Kauvoukian (1999) describes biometric technique as an automated method of recognizing an individual based on certain physiological or behavioural characteristics. Ellenbogen and Lebovic as cited in Adila (2012) argued that Biometrics originated in the identificatory systems of criminal activity developed by Alphonse Bertillon based on Francis Galton's theory of fingerprints and physiognomy. According to Martin (2011), Galton's work led to the application of mathematical models to fingerprints, phrenology, and facial characteristics, as part of "absolute identification" and "a key to both inclusion and exclusion" of populations. In the contemporary era of information technology advancement, some of the commonly used biometric techniques include fingerprints, iris scanning, facial geometry (facial recognition), hand geometry, vein pattering DNA profiling among other emerging ear and nose biometrics( Martin, 2011). These techniques have been used across many sectors in Kenya including the healthcare sector, security sector, financial sector among others. The National 


\section{International Journal of Science and Research (IJSR) \\ ISSN (Online): 2319-7064}

Index Copernicus Value (2013): 6.14 | Impact Factor (2015): 6.391

Hospital Insurance Fund (NHIF) has adopted fingerprints and iris scanning techniques to facilitate speedy and accurate registration of members.

These biometric techniques have a myriad of advantages as well as shortcomings that have been noted. As Martin (2011) notes, some of the benefits associated with the use of biometric technique include increased efficiency in service delivery, reduction in the amount of financial losses, enhanced convenience and increased customer satisfaction. However, in the event of any malfunctioning, the techniques may hinder excellent service delivery.

In addition, Adila (2012) asserts that the performance of any biometric system is often contingent upon the userknowledge of biometrics, Information Technology (IT) support, and ability to withstand large number of users, ease of customer use and promptness of IT team. Biometrics provides an efficient means of identification and verification of individuals. It is a very accurate as it provides biological characteristics that cannot be replicated easily. The technique enhances security of client information and resources as it deters forging or unauthorized use of personal identity (Adila, 2012; Bhatnagar, 2014; Jain, Ross \& Prabhakar, 2004).

An efficiently implemented biometric system improves efficiency and reduces client registration time through automatic identification. At NHIF offices in Nakuru County, the biometric registration system helps reduce the overall waiting time per client implying that many clients can be served per unit time (Adila, 2012). NHIF has rapidly moved from manual registration since 1963 to 1998 when computerization started to a more advanced biometric registration. The introduction of smart card in 2007 has now been improved to biometric technique. Taking a critical look at the year ended 2015, records at the NHIF Nakuru branch indicate a doubled member benefits, review of contribution and roll out of outpatient services. The biometric registration technique which has already started by ensuring members data is captured biometrically. In this case, fingerprints for both hands and eye scanning are captured using a special camera and the data stored in the NHIF database. The system makes it easy for accredited medical facilities within Nakuru County to identify the NHIF members. This is because NHIF Nakuru is connected to the accredited facilities via an integrated connectivity system that enables the biometric system to identify members at any of the accredited facilities. This innovative technique is aimed at member identification to avoid fraud by ensuring the benefit goes exactly to the contributor and the dependants only and no loss of funds. When this is done and during the matching phase i.e. when NHIF member is accessing services the process of identifying the member starts which is fast, reliable and efficient to the satisfaction of the members, the organization and the hospital is now able to provide services to the member having established the validity.

\subsubsection{Central Connectivity}

The central connectivity is basically used to denote the integrating of several work points from one central place (Wanjiru and Mokaya, 2012). This means that the entire
NHIF branch network is interconnected together with all the accredited hospital and clinics for ease service delivery. Through mobile and internet technologies, the members are also interconnected to the NHIF's service systems. Since the members of the fund are spread across the country, this central connection innovative strategy is aimed at real time service delivery, cost saving on communication, transport cost and convenience among others.

This central connectivity allows an organization to be easily accessed by members, customers and all stakeholders. At NHIF this means that the Nakuru residents can easily access the Fund/hospital services easily. For example, while on vacation at Mombasa, a member can simply submit contributions through any EFT bank anytime or simply pay the premiums by phone using Mpesa, and the transaction displays instant in all NHIF branches countrywide (WBGICl, 2014). Once any of these electronic or mobile technologies are used for any such transaction, the transaction details are received at the data center and further the information is shared automatically in the system and can thus be accessed at any branch. Alternatively, if he/she needs to access medical services in any accredited health facility/hospital he is simply identified biometrically. Upon transfer of a member from one work station to another, the central connectivity still makes it possible for the member to access the services of NHIF and make statutory payments without having to travel to his/her place of registration. In addition, through the central connectivity, NHIF is able to pay health institutions and facilities for the services rendered to the members and the transaction information would automatically reflect in the system. Once the information is entered in the system, it can be seen or even be updated by NHIF staff at any branch.

\subsubsection{Electronic funds transfer}

Electronic funds transfer involves the use of funds transfer, debit and credit cards in paying for goods and services. Such transfers enable the customers to optimize their consumption decisions based on the inherent security and accuracy. Electronic funds transfer entail IT based services such as Automated Teller Machines, Smart Cards, Credit cards, Debit Cards, Wire-transfer, anytime-Anywhere banking as well as phone banking services. These electronic transfer services improve the quality of customer service, increase customer satisfaction and further enhance customers-banker relationships (Simon \& Victor, 1995). As a matter of fact, the use of efficiently programmed Electronic Payment services raises the customer trust in the service provider.

In Nakuru County, there are over 50 banks, microfinance institutions and Sacco's that offer EFT services thus enabling members and organizations to transact and remit their monthly premiums to NHIF efficiently, already the several companies in Nakuru County like flower farms with both service and product firms are already using this EFT technology. In a study conducted by Jahanshahi, Rezaei, Nawaser, Ranjbar and Pitarmber (2011) on the effect of electronic commerce on organizational performance, Electronic Payment System was used as an indicator and the result revealed that the system has significant and positive impact on organizational and operational performance of banks. However, the study also indicates that electronic

\section{Volume 5 Issue 4, April 2016}




\section{International Journal of Science and Research (IJSR) \\ ISSN (Online): 2319-7064}

Index Copernicus Value (2013): 6.14 | Impact Factor (2015): 6.391

payment systems have insignificant positive impact on corporate financial performance (Jahanshahi et al, 2012). A similar study also revealed significant improvement in operational, process and financial performance (Jahanshahi, Khaksar, Paghaleh, \& Pitamber, 2011).

One of the best cash management tools available to businesses is electronic funds transfer (EFT). As the name implies, EFTs enable businesses and their customers to exchange money between each other electronically instead of using checks. EFTs is also sometimes referred to as $\mathrm{ACH}$ transactions. ACH stands for Automated Clearing House, which is the nationwide electronic payment network that allows the actual clearing of electronic payments and payment-related information between financial institutions. Payment-related information can be sent along with $\mathrm{ACH}$ transactions, a process known as electronic data interchange (EDI). These include the direct deposit; in this is perhaps the most common type of ACH payment.

Most companies can pay their NHIF contributions via direct deposit instead of paper checks. While in direct debits and credits, electronic payments can be made from NHIF to hospitals, to self-employed or other institutions when their claims or other supplier payments have been processed. Employees have grown accustomed to the convenience of receiving their pay electronically via direct deposit; this is a cost-saving innovation because payroll direct deposit is less expensive than issuing paper paychecks. For NHIF to receive ACH payments from employers and members there is benefit of cash-flow advantages because the organization is assured that payments will be made automatically on the date they're due rather than having to wait for checks that may or may not be "in the mail." there's less risk of bounced ACH transactions and the risk issue of handling cash amount is also not to be left aside. In fact due the recent increase of NHIF member contribution most big companies and government institutions are submitting more than one million shillings necessitating the CBK rules that all monies more than one million should be through EFT. Teoh (2013) discussed the factors that affect the consumer's perception of electronic payment in Malaysia. The study indicated that electronic payment systems have spread not only in Malaysia but in other countries as well. This has been due to the various campaigns launched by the banking institutions and the Central Bank of Malaysia. The results of the study reflect that perceived benefits, self-efficacy and ease of use were the main factors. However, this study did not indicate a significant relationship between security and trust with consumers' perception.

Simon \& Victor (1994) on their research of customer's risk perception of electronic payment; they noted that risk is a major determinant of whether customers adopt an electronic payment system. In Kenya; a study was conducted by Ngereza \& Iravo (2013) on the challenges influencing the implementation of electronic payment system in Kenya Airways' procurement department. The research identified that, poor security, financial issues, infrastructure, legal and political issues affected the implementation of EFT. The major problem identified was that there was no proper training done for the employees. He suggested that training should be done among the employees so that they are able to use the system more efficiently.

A number of studies have been conducted on electronic payment and factors affecting their adoption. The studies conducted by Teoh (2013) and Simon \& Victor (1994) analyzed the factors affecting consumers perception of EFT identified that just as numerous technological innovations ease of use and risk determine whether consumers adopt EFT or not. The reason EFT has not developed as much as it should is due to the lack of a conducive environment. The government has not put in place appropriate structures for its development. In Ghana, a study by Issahaku (2012) also identifies the lack of appropriate structures as the reason for the underdevelopment of EFT hence supporting the findings of the study done in Kenya by Ngereza \& Iravo (2013).

\subsubsection{Open office layout}

The NHIF Nakuru has embraced open office layout as an innovative technique of service delivery to over 10,000 registered members. In this layout, there are no distinct rooms or fully enclosed spaces. Instead, workstations are positioned together, sometimes separated by short screens or panels within one exposed floor plan. The openness improves communication and collaboration among workers, the idea of reduced concentration and productivity is minimal (NHIF, 2016).

A lack of walls or other physical barriers in open-plan office space makes it easier for NHIF employees to interact with each other on a regular basis. The constant intermingling not only generates a sense of camaraderie among personnel, but also enhances the flow of information and teamwork. Colleagues can turn to each other for advice or assistance without having to knock on doors or schedule a formal meeting. Interactions in an open-plan office space generally are more frequent and informal than in closed environments where everyone has a separate office space in organizational business advantages the increased collaboration resulting from an open office plan work space can lead to better service innovation and advancement. To the customers, the open office layout provides quick access to services from the NHIF employees since it is easier to identify the next available service desk (Brand, 2011; O’Neill, 2008)

At the same time, an open office plan layout can benefit the organization economically by reducing costs tied to construction, utilities and office equipment. For example, fewer walls mean less time and materials required to create the office space. Having a single work space also may reduce heating/cooling and electricity expenses thanks to improved flow of air and light. Organization can save on equipment investment as well, since communal spaces promote shared use of resources, such as printers, copiers and staplers (O'Neill, 2008). Therefore this open office plan space is expected to provide greater flexibility to accommodate evolving personnel needs in service delivery.

\subsubsection{NHIF ACT}

The National Hospital Insurance Fund (NHIF) was first established in 1966 soon after Kenya attained independence as a primary provider of health insurance to the citizens of 


\section{International Journal of Science and Research (IJSR) \\ ISSN (Online): 2319-7064 \\ Index Copernicus Value (2013): 6.14 | Impact Factor (2015): 6.391}

Kenya. Afterwards, the NHIF Act was enacted in 1998 to make the fund an autonomous institution governed by a Board of Directors with representatives from the civil society, employers and local governments. The Health Insurance Act of 1998 does not distinguish formal and informal sectors, and makes membership mandatory for all Kenyans who have attained the majority age of 18 years of age. According to the Act, the National Hospital Insurance Fund (NHIF) requires compulsory membership for all salaried employees with premium contributions automatically deducted through payroll. Contributions are calculated on a graduated scale based on gross income, with a majority contributing between KES 150 to KES 1700 per month. In practice, however, while Kenya has achieved high levels of coverage of the formal sector, coverage of the informal sector has proved more challenging.

In fact, the NHIF Act has since undergone several amendments over the years and such amendments have necessitated innovations and changes in the NHIF systems and thus influenced service delivery. For example, the NHIF amendment bill of 2015 outlines the relationship between the national and devolved governments in Kenya with regards to delivery of healthcare services. The bill affects the functions and powers of county governments by influencing the running of various health facilities managed by the county governments. In this case, the County government of Nakuru is not an exception as it is among the county governments affected by the NHIF Amendments Bill of 2015. The NHIF ACT also affects service delivery by defining the mandatory contribution per member and the extent to which the NHIF members can get services.

\subsubsection{Service Delivery}

Efficient and effective service delivery requires an elaborate evaluation of the user needs and expectations; linking service development and delivery to the user needs; evaluating and monitoring service performance and outcomes; ensuring sustainability of improved service delivery in line with the user demands and developing the skills needed to sustain service delivery and sharing and applying best practices and knowledge across the organization (Emrouznejad, \& Cabanda, 2014). Providing quality service is about satisfying and even enhancing the organization's capability to deliver much more value than the customer's expectation. This means it's the difference between customer expectation prior to the service encounter and the actual perceived service that the organization provides (Oosterom, 2007). In addition, innovative and top quality service provision makes an organization reliable hence delivering customer satisfaction. Besides the efficiency and effectiveness, service delivery is hinged on the appropriateness and timeliness of the strategy employed. Performance of these innovation strategies may not be devoid of errors, especially due to different systems and parties involved, system breakdown, congestion in peak periods, complexity and inflexibility in service delivery. For an organization to compete in the turbulent market environment coupled with fast technological changes, it is ideal to do things differently and innovate in a timely manner to safeguard market territories and stay ahead of the competition (Oosterom, 2007; Chemengich, 2013). The organization should not underestimate the competitive challenge faced as it would be risky if competitors react more to potential challenges the same way.

\subsection{Conceptual framework}

Conceptual framework consists of a number of independent and intervening variables that profoundly influence the dependent variable in this study.

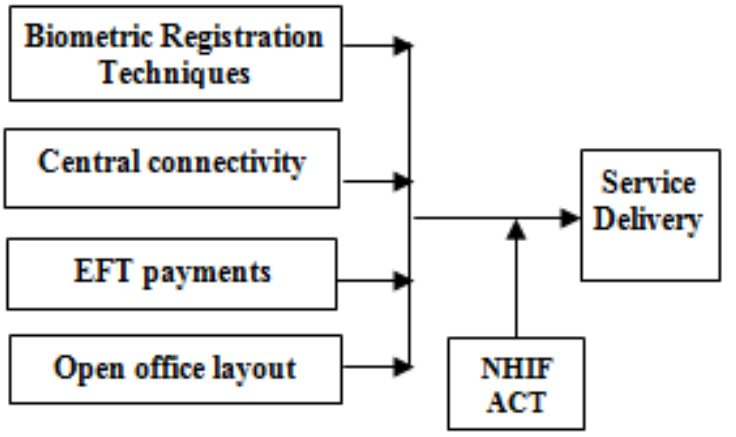

Figure 1: Conceptual Framework

\section{Methodology}

The study adopted a descriptive research design with a census strategy. The target population of this study was 60 employees consisting of managers and staff members from all functional departments of NHIF, Nakuru branch. Census of 60 respondents was conducted in order for the researcher to obtain accurate information from the population. A pilot study was conducted at NHIF, Kericho branch using six questionnaires. The questionnaire items were tested for validity prior to the actual data collection and further the research instrument tested for reliability and the researcher ascertained Cronbach alpha $(\alpha \geq 0.7)$ for all the variables as shown in table 1.

Table 1: Reliability statistics

\begin{tabular}{|c|c|c|}
\hline Constructs & $\begin{array}{l}\text { No. of } \\
\text { Items } \\
\text { Tested }\end{array}$ & $\begin{array}{c}\text { Cronbach's } \\
\text { Alpha }(\alpha)\end{array}$ \\
\hline i. Biometric Registration Techniques & 8 & 0.946 \\
\hline ii. Central Connectivity & 7 & 0.736 \\
\hline iii.Electronic Fund Transfer Payments & 7 & 0.936 \\
\hline iv. Open office Layout & 5 & 0.755 \\
\hline
\end{tabular}

The researcher administered structured questionnaires via a drop and pick method to collect primary data from the population. A Pearson correlation analysis was conducted to determine the relationship between diversification strategies and competitive performance. In addition, a regression analysis was done and a two tailed significance test was also conducted to test the statistical significance of the relationships. The following regression equation was used to determine the effect of the independent variables on the dependent variable:

i. $Y=a+\beta_{1} C_{1}+\beta_{2} C_{2}+\beta_{3} C_{3}+\beta_{4} C_{4}+e$. The results of the study were presented using tables. 


\section{International Journal of Science and Research (IJSR) \\ ISSN (Online): 2319-7064 \\ Index Copernicus Value (2013): 6.14 | Impact Factor (2015): 6.391}

\section{Research Findings}

The study focused on how innovative strategies influence service delivery at NHIF, Nakuru branch. The innovative strategies analyzed in this case included biometric registration techniques, central connectivity, electronic funds transfer payments and open office layout. Correlating each of the aforesaid innovative strategies against the service delivery at NHIF enabled the researcher to determine their respective relationships. In order to assess the extent to which the innovative strategies adopted at NHIF, Nakuru related to service delivery, multiple regression analysis was conducted

\subsection{Relationship between Biometric Registration Techniques and Service Delivery}

This section outlines the results of correlation analysis between biometric registration techniques and service delivery by NHIF, Nakuru branch (Table 2). The findings on this section are interpreted and further discussed accordingly.

Table 2: Correlation between Biometric Registration Techniques and Service Delivery

\begin{tabular}{|l|c|c|}
\hline \multicolumn{2}{|c|}{} & Service Delivery \\
\hline \multirow{2}{*}{$\begin{array}{l}\text { Biometric } \\
\text { Registration }\end{array}$} & Pearson Correlation & $.675^{* *}$ \\
\cline { 2 - 3 } & Sig. (2-Tailed) & .000 \\
\cline { 2 - 3 } & $\mathrm{N}$ & 58 \\
\hline \multirow{2}{*}{$*$. Correlation is Significant At The 0.05 Level (2-Tailed). } \\
\hline
\end{tabular}

According to the study findings, it was observed that the relationship between biometric registration techniques and service delivery was positive, strong and statistically significant $(r=0.675 ; p<0.05)$. The study observed that fingerprinting and iris techniques are critical for NHIF and its stakeholders to enhance service delivery. This implied that through the use of biometric registration techniques, NHIF is capable of store, maintain and generate vital information about the customers when the need arises.

\subsection{Relationship between Central Connectivity and Service Delivery}

In line with the second objective of the study, this section outlines the results of the relationship between central connectivity and service delivery by NHIF, Nakuru branch. The findings on this section are as shown in (Table 3).

Table 3: Correlation between Central Connectivity and Service Delivery

\begin{tabular}{|c|c|c|}
\hline \multicolumn{2}{|c|}{} & Service Delivery \\
\hline \multirow{3}{*}{$\begin{array}{c}\text { Central } \\
\text { Connectivity }\end{array}$} & Pearson Correlation & $.557^{* *}$ \\
\cline { 2 - 3 } & Sig. (2-Tailed) & .000 \\
\cline { 2 - 3 } & $\mathrm{N}$ & 58 \\
\hline *. Correlation Is Significant At The 0.05 Level (2-Tailed). \\
\hline
\end{tabular}

The study revealed that the relationship between central connectivity and service delivery was positive, strong and statistically significant $(r=0.557 ; \mathrm{p}<0.05)$. The study observed that operating an efficient central connectivity for NHIF and its stakeholders is necessary to enhance service delivery. This implied that through the central connectivity,
NHIF is capable of sharing vital information with members, employees and the accredited health facilities.

\subsection{Relationship between Electronic Funds Transfer Payments and Service Delivery}

This section outlines the results of correlation analysis between Electronic Funds Transfer Payments and service delivery by NHIF, Nakuru branch. Table 6 presents the findings on this section. From the study findings, it was revealed that the relationship between electronic funds transfer payments and service delivery was positive, strong and statistically significant $(r=0.608$; $\mathrm{p}<0.05)$. The study observed that the adoption of the EFT payments by NHIF and its stakeholders is necessary to enhance service delivery. This implied that through the EFT payment systems, transactions can be done even during weekends and after normal office hours. This further meant that the members can remit payments using internet and mobile technologies without having to queue at the NHIF offices.

Table 4: Correlation between Electronic Funds Transfer Payments and Service Delivery

\begin{tabular}{|c|c|c|}
\hline \multicolumn{2}{|c|}{} & Service Delivery \\
\hline \multirow{2}{*}{$\begin{array}{c}\text { Electronic Funds } \\
\text { Transfer Payments }\end{array}$} & Pearson Correlation & $.608^{* *}$ \\
\cline { 2 - 3 } & Sig. (2-tailed) & .000 \\
\cline { 2 - 3 } & $\mathrm{N}$ & 58 \\
\hline \multirow{2}{*}{$* *$. Correlation is significant at the 0.05 level (2-tailed). } \\
\hline
\end{tabular}

\subsection{Relationship between Open Office Layout and Service Delivery}

The study also examined how open office layout influenced service delivery by NHIF, Nakuru branch. This section outlines the results of correlation analysis between open office layout and service delivery by NHIF, Nakuru branch. Table 5 illustrates the relevant correlation findings.

Table 5: Correlation between Open Office Layout and Service Delivery

\begin{tabular}{|c|c|c|}
\hline \multicolumn{2}{|c|}{} & Service Delivery \\
\hline \multirow{2}{*}{$\begin{array}{c}\text { Open Office } \\
\text { Layout }\end{array}$} & Pearson Correlation & $.513^{* *}$ \\
\cline { 2 - 3 } & Sig. (2-tailed) & .000 \\
\cline { 2 - 3 } & $\mathrm{N}$ & 58 \\
\hline \multirow{2}{*}{$* *$ Correlation is significant at the 0.05 level (2-tailed). } \\
\hline
\end{tabular}

The study revealed that the relationship between open office layout and service delivery was positive, strong and statistically significant $(r=0.513 ; \mathrm{p}<0.05)$. The study observed that the adoption of the open office layout at NHIF and enhances speed of service delivery, sharing of vital information and resources amongst employees and further improved the spirit of teamwork.

\subsection{Relationship between Innovative Strategies and Service Delivery}

This study assessed how innovative strategies influenced service delivery at NHIF, Nakuru Branch. Table 8, 9 and 10 show the results of multiple regression analysis. 


\section{International Journal of Science and Research (IJSR) \\ ISSN (Online): 2319-7064 \\ Index Copernicus Value (2013): 6.14 | Impact Factor (2015): 6.391}

Table 6: Model Summary

\begin{tabular}{|c|c|c|c|c|}
\hline Model & $\boldsymbol{R}$ & $\boldsymbol{R}$ Square & $\begin{array}{c}\text { Adjusted } \boldsymbol{R} \\
\text { Square }\end{array}$ & $\begin{array}{c}\text { Std. Error of the } \\
\text { Estimate }\end{array}$ \\
\hline 1 & $.773^{a}$ & .598 & .568 & .45022 \\
\hline
\end{tabular}

a. Predictors: (Constant), Open Office Layout, Electronic Funds Transfer, Biometric Registration Techniques

Table 8 outlines the results of coefficient of determination $\left(r^{2}\right)$ and correlation coefficient $(R)$. The results of $\left(r^{2}=0.568\right)$ and $(\mathrm{R}=0.773)$ reflected a strong association between the innovative strategies adopted and service delivery at NHIF, Nakuru Branch.

Table 7: ANOVA

\begin{tabular}{|c|c|c|c|c|c|c|}
\hline \multicolumn{7}{|c|}{ ANOVA $^{a}$} \\
\hline & Model & $\begin{array}{c}\text { Sum of } \\
\text { Squares }\end{array}$ & $d f$ & $\begin{array}{l}\text { Mean } \\
\text { Square }\end{array}$ & $F$ & Sig. \\
\hline \multirow{3}{*}{1} & Regression & 15.993 & 4 & 3.998 & 19.725 & $.000^{\mathrm{b}}$ \\
\hline & Residual & 10.743 & 53 & .203 & & \\
\hline & Total & 26.736 & 57 & & & \\
\hline \multicolumn{7}{|c|}{ A. Dependent Variable: Service Delivery } \\
\hline \multicolumn{7}{|c|}{$\begin{array}{c}\text { B. Predictors: (Constant), Open office layout, Central } \\
\text { Connectivity, Biometric Registration Techniques, Electronic } \\
\text { Funds Transfer }\end{array}$} \\
\hline
\end{tabular}

Table 7 presents the findings of analysis of variance (ANOVA). The analysis indicated that the innovative strategies had significant effect on service delivery at NHIF, Nakuru Branch ( $\mathrm{F}=19.725 ; \mathrm{p}<0.05)$ at $95 \%$ degree of confidence. These findings were based on the importance of adopting innovative strategies for NHIF to enhance the quality of service delivery.

Table 8: Results of Regression Analysis

\begin{tabular}{|c|c|c|c|c|c|c|}
\hline \multicolumn{7}{|c|}{ Coefficients $^{\mathrm{a}}$} \\
\hline & \multirow[t]{2}{*}{ Model } & \multicolumn{2}{|c|}{$\begin{array}{c}\text { Unstandardized } \\
\text { Coefficients }\end{array}$} & \multirow{2}{*}{$\begin{array}{c}\begin{array}{c}\text { Standardized } \\
\text { Coefficients }\end{array} \\
\text { Beta }\end{array}$} & \multirow[b]{2}{*}{$\mathbf{T}$} & \multirow[b]{2}{*}{ Sig. } \\
\hline & & B & $\begin{array}{l}\text { Std. } \\
\text { Error }\end{array}$ & & & \\
\hline \multirow{5}{*}{1} & (Constant) & -1.341 & .775 & & -1.729 & .090 \\
\hline & \begin{tabular}{|c|} 
Biometric \\
Registration \\
Techniques
\end{tabular} & .507 & . 122 & .436 & 4.147 & .000 \\
\hline & \begin{tabular}{|c|} 
Central \\
Connectivity
\end{tabular} & .270 & .244 & .214 & 1.107 & .273 \\
\hline & $\begin{array}{l}\text { Electronic } \\
\text { Funds } \\
\text { Transfer } \\
\end{array}$ & .144 & .224 & .132 & .642 & .523 \\
\hline & $\begin{array}{c}\text { Open Office } \\
\text { Layout }\end{array}$ & .346 & .171 & .204 & 2.020 & .048 \\
\hline
\end{tabular}

The results of the regression analysis (Table 4.17) were interpreted using the following regression function: $\mathrm{Y}=\beta_{\mathrm{o}}+$ $\beta_{1} C_{1}+\beta_{2} C_{2}+\beta_{3} C_{3}+\beta_{4} C_{4}+$ e where $Y, C_{1}, C_{2}, C_{3}, C_{4}$ represented service delivery, biometric registration techniques, central connectivity, electronic funds transfer payments and open office layout respectively. The results were interpreted as follows: $\mathrm{Y}=-1.341+0.507 \mathrm{C}_{1}+0.270 \mathrm{C}_{2}$ $+0.144 \mathrm{C}_{3}+0.346 \mathrm{C}_{4}$. The findings implied that the first null hypothesis was rejected $(\mathrm{t}=4.147 ; \mathrm{p}<0.05)$. The findings further implied that the second null hypothesis was not rejected $(\mathrm{t}=1.107 ; \mathrm{p}>0.05)$. The third null hypothesis was not rejected $(\mathrm{t}=0.642 ; \mathrm{p}>0.05)$ and the fourth null hypothesis was rejected $(\mathrm{t}=2.020 ; \mathrm{p}<0.05)$. The study findings further indicated that the service delivery at NHIF Nakuru was influenced by 0.507 biometric techniques, 0.270 central connectivity, 0.144 electronic funds transfer payments and 0.346 open office layout. Besides, the results of the study indicated that the innovative strategies jointly influenced the service delivery at NHIF, Nakuru branch $(\mathrm{t}=-1.729 ; \mathrm{p}>0.05)$.

\section{Conclusion and Recommendations}

The findings of the analysis of the factors associated with adoption of biometric registration techniques as it relates with service delivery indicated that the staff members of NHIF were aware of the biometric techniques used at NHIF. The findings also indicated that both the iris and fingerprint techniques adopted are relevant to achievement of the organization's objectives. The study further established that the biometric techniques enhance the efficiency of service delivery and reduce financial losses to the organization. The study also revealed that the biometric registration techniques enable accurate verification of members and that the techniques make it possible to serve many customers and enhance security of client information.

The findings of the analysis of the factors associated with adoption of open office layout in relation to service delivery indicated that the employees understand the open office layout. It was also emerged that the adoption of open office layout enhances service delivery at NHIF and that the layout creates an encouraging environment that enables the staff members to share responsibilities and resources. Accordingly, the findings of the study showed that open office layout enhances a sense of camaraderie among employees, information flow and teamwork.

To enhance service delivery at NHIF, the following recommendations were imperative: The biometric registration techniques which elicited significant results from the study should be maintained and enhanced to cater for the growing population of customers. The open office layout which positively and significantly impacted service delivery should be adopted in full so that all managers and employees can work in the same environment irrespective of the position held in the organization. This is because key managers in the branch still operate in enclosed offices and so their interactions with other employees are limited. Also, enhancement of central connectivity systems and equipments is recommended to help avert the menace of system stoppages.

It was further recommended that the organization should ensure its electronic funds transfer payments are leveraged with advanced technology to improve service quality and performance of the organization. In addition, That the growing number of customers and the subsequent increment of the number of employees requires additional space to maintain the open office layout which has been observed to be essential for improved service delivery and performance of the organization. It is also recommended that the 


\section{International Journal of Science and Research (IJSR) \\ ISSN (Online): 2319-7064}

Index Copernicus Value (2013): 6.14 | Impact Factor (2015): 6.391

organization should invest more in developing the capacities of its workforce and in particular provide incentives to motivate the employees to further their studies in information systems and their applicability to service delivery. This will enable the employees acquire skills requisite for the adoption, implementation and operation of new innovative and system as a means of leveraging service delivery.

This study provided relevant insight on the adoption of innovative strategies on service delivery at NHIF, Nakuru branch. It is important that further research is carried out to assess implications of central connectivity in light of the organizational and stakeholder challenges relating to the implementation of advanced central connectivity systems on service delivery

\section{References}

[1] Adila, M. M. (2012). Biometric Authentification Systems and Service Delivery In Healthcare Sector in Kenya. Nairobi, UON Press.

[2] Bhargava, S, \&. Welford, R. (2009). Corporate Strategy and the Environment. Journal of European Industrial Training.vol 33(1), pp. 1-26.

[3] Brand, J. L. (2011). Should Your Company Transition from Traditional Private Offices to an Open Office Plan. Knowl Workplace Research. pp. 1-4.

[4] Bhatnagar, S. (2014). Public Service Delivery: Role of Information and Communication Technology in Improving Governance and Development Impact. ADB Economics Working Paper No. 391. pp. 1-25.

[5] Chemengich, M. (2013). Managing Strategic Change in Public Sector. Standard Research Journal of Business Management, Vol 1(1): 1-40.

[6] Chuttur, M. (2009). Overview of the Technology Acceptance Model: Origins, Developments and Future Directions. Sprouts: Working Papers on Information Systems, Technology Acceptance Model Review, vol. 9 (37), pp. 1-23.

[7] Cohen. S, \& Eimicke, W. (1996). Understanding and Applying Innovation Strategies in the Public Sector. 57 th Annual National Conference of the American Society for Public Administration, vol. 1: pp. 1-21.

[8] Donaldson, T. A. (1995). "The Stakeholder Theory of the Corporation: Concepts, Evidence, and Implications. Academy of Management in organisation, vol. 20(1), pp. 65-91.

[9] Emrouznejad. A, \& Cabanda, E. (2014). Managing Service Productivity: Using Frontier Efficiency Methodologies and Multicriteria Decision Making for Improving Service Performance. New York. Springer International Publishers.

[10] Gallouj, C., \& Gallouj, F. (2000). Neo-Schumpeterian Perspectives on Innovation in Services. In Bodem, M. \& Miles, I. (eds), Services and the Knowledge-Based Economy. London: Continuum, Vol. 24 (5), pp. 21-37.

[11] Issahaku, H. (2012). Challenges of Electronic Payment Systems in Ghana: The Case of eZWICH, American Journal of Business and Management, vol. 1(3), pp. 8795.
[12] Jahanshahi, A. A., Khaksar, S. M. S., Paghaleh, M. J., \& Pitamber, B. K. (2011). The Application of Electronic Commerce Among Small and Medium Enterprises: From Business Processes View. International Journal of Busines and Social Science. Vol. 2(5), 142-149.

[13] Jahanshahi, A. A., Rezaei M., Nawaser, K., Ranjbar, V., \& Pitamber, B. K. (2012). Analyzing the Effects of Electronic Commerce on Organizational Performance: Evidence from Small and Medium Enterprises. African Journal of Busines Management. Vol 6(15). pp. 64866496.

[14] Jain, A. K., Ross, A., \& Prabhakar, S. (2004). An Introduction to Biometric Recognition. IEEE Transactions on Circuits and Systems for Video Technology. vol. 14(1), pp. 4-21.

[15] Johnson, R. (1995). The Determinants of Service Quality: Satisfiers and Disatisfiers. International Journal of Service Industry Management, vol. 6(5); pp. 53-71.

[16] Maharshi Dayanand University, Rohtak. (2004). Strategic Management: M.Com (Final). New Delhi: Excel Books PVT Ltd.

[17] Martin, A.K.(2011). Envisioning Technology through Discourse: A case Study of Biometrics in the National Identity Scheme in the United Kingdom. $\mathrm{PhD}$ thesis, The London School of Economics and Political Science (LSE).

[18] Nakuru County Government. (2016). Strategic Plan 2013-2016. County Government of Nakuru.Nakuru. Government publishers.

[19] National Hospital Insurance Fund. (2016). NHIF Newsletter. Nairobi. NHIF.

[20] Oosterom, W. (2007). The Road Ahead for Public Service Delivery: Delivering on the Customer Promise. Public Sector Research Centre, vol 2(5), pp 8-10.

[21] O'Neill, M. (2008) Open Plan and Enclosed Private Offices: Research Review and Recommendations. Knoll Workplace Research. Knoll, pp. 1-5.

[22] Pisano, G. P. (2015). You Need an Innovation Strategy. Harvard Business Review, June, 2015 Issue. pp. 48-59.

\section{Author Profile}

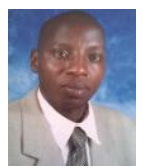

Earnest Seme Nyaberi holds diploma in Busness Management (University of Nairobi, Kenya) Bachelor of Commerce-Marketing (Kabarak University, Kenya), Masters of Busness Admnistration-Strategic Management (Jomo Kenyatta University of Agriculture and Technology, Kenya). 